\title{
Comparison of Neurite Outgrowth Induced by Intact and Injured Sciatic Nerves: A Confocal and Functional Analysis
}

\author{
Eric Agius and Philippe Cochard \\ Centre de Biologie du Développement, Centre National de la Recherche Scientifique Unité Mixte de Recherche 5547, \\ affiliée à l'Institut National de la Santé et de la Recherche Médicale, Université Paul Sabatier, 31062 Toulouse, France
}

\begin{abstract}
Mechanisms regulating axon growth in the peripheral nervous system have been studied by means of an in vitro bioassay, the tissue section culture, in which regenerating neurons are grown on substrata made up of tissue sections. Sections from intact and degenerated sciatic nerves proved to be different in their ability to support neurite outgrowth of embryonic chick sensory neurons from both qualitative and quantitative points of view. On denervated nerve sections, the total length of neurites elaborated per neuron was almost twice that found on intact nerve sections. In addition, confocal microscopy revealed a striking difference between intact and denervated nerve substrata: on denervated nerve sections, neurites grew inside the internal structures of endoneurial Schwann cell tubes, within the underlying tissue sections, whereas on intact nerve sections neurites extended along endoneurial basal laminae but never entered Schwann cell tubes. Perturbation experiments were used to analyze some of the molecular determinants that
\end{abstract}

control neurite outgrowth in this system. Antibodies directed against the $\beta 1$-integrin subunit inhibited neurite extension on both normal and degenerated rat sciatic nerve tissue. Strikingly, however, differential inhibition was observed using antibodies directed against extracellular matrix molecules. Anti-laminin-2 (merosin) antibodies drastically reduced both the percentage of growing neurons and the total length of neurites on denervated nerve sections, but they did not modify these parameters on sections of normal nerve. Taken together, these results suggest that laminin-2/merosin promotes neurite outgrowth in peripheral nerve environments but only after Wallerian degeneration, which is when axons are allowed to extend within endoneurial tubes.

Key words: nerve fiber growth; axon regeneration; peripheral nervous system; Wallerian degeneration; rat sciatic nerve; extracellular matrix; integrin; merosin; cryoculture; bioassay; confocal microscopy
In Mammals, peripheral nerve injuries are followed by Wallerian degeneration in the distal stump of the nerve. This degeneration process is thought to be a prerequisite for axonal regeneration, because the intact proximal stump of a severed peripheral nerve does not support sensory axon regeneration (Langley and Anderson, 1904; Ramon y Cajal, 1928). Wallerian degeneration is accompanied by complex cellular and molecular processes and in particular induces modifications in extracellular matrix (ECM) composition (Cornbrooks et al., 1983; Martini et al., 1990). However, the basal lamina tube that surrounded the original fiber is left intact, and together with dividing Schwann cells it forms endoneurial Schwann cell tubes, also called bands of Büngner, which guide regenerating nerve fibers.

ECM molecules are recognized by specific neuronal receptors, the most prevalent being integrins (Haas and Plow, 1994; Luckenbill-Edds, 1997). In in vitro systems, a large variety of integrins and ECM molecules have been shown to regulate neu-

Received Aug. 4, 1997; revised Oct. 17, 1997; accepted Oct. 22, 1997.

This work was supported by Centre National de la Recherche Scientifique, Centre National d'Etudes Spatiales, and Direction des Recherches, Etudes et Techniques. E.A. was supported by a doctoral fellowship from Ministère de l'Enseignement Supérieur et de la Recherche. We thank Dr. A. M. Duprat for constant support, valuable discussions, and critical reading of this manuscript. We are also indebted to Dr. J. Smith for reviewing and correcting this manuscript.

Correspondence should be sent to Dr. P. Cochard, Centre de Biologie du Développement, Centre National de la Recherche Scientifique Unité Mixte de Recherche 5547, Université Paul Sabatier, 118 route de Narbonne, bât 4R3, 31062 Toulouse Cedex, France.

Dr. Agius's present address: Howard Hughes Medical Institute, Department of Biological Chemistry, University of California Los Angeles, Los Angeles, CA 90024-1737.

Copyright (C) 1997 Society for Neuroscience $\quad 0270-6474 / 97 / 180328-11 \$ 05.00 / 0$ ron process outgrowth (Venstrom and Reichardt, 1993), but the role of these components in controlling nerve fiber regeneration in situ remains elusive, despite a number of in vivo attempts (Toyota et al., 1990; Wang et al., 1992; Kauppila et al., 1993). In any case, it may be difficult to interpret in vivo experiments, because complex accompanying events such as Schwann cell migration and macrophage invasion, which are also regulated by cell-matrix interactions, may be perturbed by the treatments. A simpler approach is the "cryoculture" bioassay (Carbonetto et al., 1987; Covault et al., 1987; Sandrock and Matthew, 1987), also referred to as "tissue section culture" (Crutcher, 1989). In this technique, neurons or neuronal explants are cultivated on cryostat sections of various tissues, thus allowing growth cones to interact directly with tissue substrata. Previous experiments have already shown that embryonic neurons can extend long neurites on peripheral nerve sections (Carbonetto et al., 1987). Moreover, adult sensory neurons have been shown to extend neurites only on sections of nerves that have undergone Wallerian degeneration, thus mimicking their in vivo behavior (Bedi et al., 1992).

In an attempt to understand how Wallerian degeneration affects nerve fiber growth, we have used the cryoculture bioassay and confocal microscopy to compare neurite outgrowth of immature neurons induced by normal and degenerated sciatic nerve substrata. In addition, by using blocking antibodies to perturb interactions between growing neurites and their natural environment, we have defined some of the interactions leading to nerve fiber outgrowth on each type of nerve substrate. We demonstrate that the growth of chick sensory neurons is increased on denervated nerves compared with normal nerves. Interestingly, this 
increase was correlated with the ability of neurites to enter Schwann cell tubes in the underlying section substrate. Anti- $\beta 1$ integrin antibodies blocked growth at similar levels on intact and denervated nerve sections. Anti-merosin antibodies also inhibited neurite outgrowth, but significant inhibition was only observed on denervated substrata, suggesting that the growth-promoting ability of this ECM molecule is increased after denervation, again perhaps attributable to the ability of nerve fibers to enter Schwann cell tubes.

\section{MATERIALS AND METHODS}

\section{Preparation of lesioned and nonlesioned tissue substrata}

Adult Wistar rats (IFFA Credo, Arbresle, France) (200-250 gm) were anesthetized with an intraperitoneal injection of chloral hydrate $(0.5$ $\mathrm{ml} / 100$ gm body weight, $8 \%$ solution in PBS). The right sciatic nerve was exposed and transected with sterile surgical scissors between two ligatures. The distal stump was displaced to prevent contamination by regenerating axons. The wound was closed with surgical clips. Rats were killed by $\mathrm{CO}_{2}$ inhalation $15 \mathrm{~d}$ after lesion. The distal portion of the transected sciatic nerve and the contralateral, nonlesioned sciatic nerves were cut into segments of $0.5 \mathrm{~cm}$ in length. The nerves segments, unfixed, were desheathed and rapidly frozen in isopentane cooled by liquid nitrogen. Longitudinal sections $(14 \mu \mathrm{m})$ were cut onto a cryomicrotome, collected on 14-mm-diameter glass coverslips, and stored at $4^{\circ} \mathrm{C}$ before use or for several weeks at $-20^{\circ} \mathrm{C}$ until required.

\section{ECM molecule substrata}

Control experiments involving purified ECM molecules were performed in Terasaki plates (Nunc, Naperville, IL). For the laminin-1 and laminin-2 substrata, the Terasaki microwells were precoated with polyornithine $(1 \mathrm{mg} / \mathrm{ml})$ (Sigma, St. Louis, MO) in distilled water for $30 \mathrm{~min}$. Excess solution was removed and microwells were rinsed with PBS and incubated for $2 \mathrm{hr}$ at $37^{\circ} \mathrm{C}$ with a $10 \mu \mathrm{g} / \mathrm{ml}$ solution of laminin- 1 or laminin-2 (human merosin; Chemicon, Temecula, $\mathrm{CA}$ ) in $\mathrm{Ca}^{2+}, \mathrm{Mg}^{2+}$ free PBS. Two laminin-1 preparations purified from Engelbreth-HolmSwarm (EHS) tumor were tested: one was a generous gift from Dr. C. Henderson (INSERM, U. 382, IBDM, Marseille, France), and the other was purchased from Sigma. The fibronectin substratum was prepared by incubating microwells for $2 \mathrm{hr}$ with $10 \mu \mathrm{l}$ of a $100 \mu \mathrm{g} / \mathrm{ml}$ rat fibronectin solution (Sigma) in $\mathrm{Ca}^{2+}, \mathrm{Mg}^{2+}$-free PBS. Excess solution was removed, and the wells were left to dry. In all cases, the microwells were rinsed twice with DMEM medium before use.

\section{Preparation of purified neuronal cultures}

Chicken sensory neurons were used as the main neuronal model in this study. Two considerations dictated the choice to use chick neurons. First, E13 DRG neurons are much easier to purify and rid of contaminating non-neuronal cells than newborn rat DRG neurons (Tuttle and Matthew, 1995). Second, their neurites can be specifically distinguished from axons running in the underlying nerve substrata by species-specific anti-NCAM antibodies. Dorsal root ganglia (DRG) were dissected from E13 chick embryos and dissociated as described previously (Agius et al., 1996). The resulting cell suspension $(25,000$ neurons/ml), containing a $90 \%$ pure neuronal population, was plated onto tissue section-coated coverslips and placed in $16 \mathrm{~mm}$ wells of four-well plastic dishes (Nunc). For control experiments performed in Terasaki microwells, 300 neurons were seeded in $10 \mu \mathrm{l}$ of culture medium. Medium was composed of DMEM completed with $10 \%$ FCS (Flow Laboratories, Irvine, UK), $125 \mathrm{ng} / \mathrm{ml}$ of $7 \mathrm{~S}$ NGF (Sigma), $50 \mu \mathrm{g} / \mathrm{ml}$ of gentamycin, and $2 \mathrm{~mm}$ L-glutamine. In perturbation experiments, the perturbing agent was added to the culture medium before the cells were seeded. In some experiments, neurons from E13 chicken sympathetic ganglia or from newborn mouse DRG ganglia were also used, following the same protocol as above.

\section{Antibodies}

The monoclonal antibodies (mAbs) directed against the chick $\beta 1$ integrin subunit, JG22 (David I. Gottlieb; Greve and Gottlieb, 1982), V2E9 (Alan F. Horwitz; Hayashi et al., 1990), and against chicken N-CAM, 5e (Urs Rutishauser), were obtained from the Developmental Studies Hybridoma Bank maintained by the Department of Pharmacology and Molecular Sciences, The Johns Hopkins University School of Medicine, Baltimore, MD 21205, and the Department of Biological
Sciences, University of Iowa, Iowa City, IA 52242, under contract N01HD-6-2915 from the National Institute of Child Health and Human Development. The mAb against the A2B5 epitope was kindly provided by Dr. M. Fauquet (URA CNRS 2115, Université Paris). The mAb against the $N$-cadherin (clone GC-4) was purchased from Sigma. All $\mathrm{mAbs}$ were used at a final concentration of $25 \mu \mathrm{g}$ of $\mathrm{Ig} / \mathrm{ml}$, except where stated otherwise. The polyclonal antibody directed against EHS tumor laminin (laminin-1) has been characterized previously (Carbonetto et al., 1987). It also recognizes laminin-2 (merosin), and thus will be named anti-laminin-1/2 in the text. For inhibition assays, it was used at a 1:500 dilution. Other antisera directed against laminin-1 and against rat fibronectin and an $\mathrm{mAb}$ directed against the $\beta 2$ chain of human merosin (laminin-2), which cross-reacts with rat laminin-2, were purchased from Chemicon and were used at a concentration of $25-50 \mu \mathrm{g}$ of $\mathrm{Ig} / \mathrm{ml}$ for inhibition assays.

\section{Analysis of neurite outgrowth}

The effects of peptides and antibodies on neurite outgrowth were determined both by counting the number of neurons with neurites and by measuring the neurite length on camera lucida drawings of randomly selected neurons. Neurites of growing chick sympathetic or sensory neurons could not be visualized directly by phase contrast microscopy because of the thickness of tissue section substrata; therefore, neurons were immunostained as described under immunocytochemistry. To visualize Schwann cells or fibroblasts that may contaminate the cultures, some preparations were stained directly with the vital dye calcein-AM $(2.5 \mu \mathrm{M})$ (Molecular Probes, Eugene, OR).

Counts of growing neurons. Individual and reaggregated neurons attached to the tissue sections were counted on the entire coverslip, with an average value of $\sim 1000$ neurons/dish. When cell numbers exceeded this value, cell counts were limited to 1200 neurons/coverslip. To avoid possible artifacts attributable to the variability in neuronal numbers, care was taken to include only those cultures with an equivalent neuronal density; i.e., cultures containing too many or too few neurons were discarded. Growing neurons were defined as those extending nerve processes longer than two cell body diameters. Neurite outgrowth was expressed as the percentage of neurons with neurites in the total population of attached neurons. In perturbation experiments, inhibition of neurite outgrowth was calculated by the following formula:

inhibition of neurite outgrowth $=$

$$
\left\{1-\frac{\% \text { of growing neurons (perturbed) }}{\% \text { of growing neurons (control) }}\right\} \times 100 \text {. }
$$

Scores were averaged from two to three coverslips per experiment, and results were expressed as the mean \pm SEM of at least three independent experiments (see Results).

Determination of neurite length and of number of primary neurites per neuron. After the immunostaining procedure, neurons were randomly selected and drawn using a camera lucida system. The length of the entire neuritic arborization was measured, and the number of primary neurites per neuron was determined. Approximately 100 neurons drawn from at least three independent experiments were taken into account for each experimental condition.

\section{Control experiments}

In all perturbation experiments, the efficacy and possible toxicity of antibody and peptide preparations were controlled on microcultures of the same suspension of purified DRG and sympathetic neurons grown in Terasaki dishes on the relevant substrata (laminin-1, laminin-2, or fibronectin). All neurons in each microwell were counted, and scores were averaged from 4-10 microwells per condition. Results were expressed as the mean \pm SEM of at least three independent experiments. Cytotoxicity of the various perturbing reagents was also checked in preliminary experiments, using calcein-AM and Ethidium homodimer-1 (live/dead, viability/cytotoxicity kit; Molecular Probes). At the appropriate time, the cytotoxicity test reagent was added to the culture medium as indicated by the supplier.

\section{Immunocytochemistry}

For cell counts, after $2 \mathrm{~d}$ of culture, the preparations were fixed for 15 min with a $3.5 \%$ formaldehyde solution. Cultures were rinsed, preincubated for $1 \mathrm{hr}$ with a PBS solution containing 1\% lyophilized skimmed milk, rinsed again in PBS, and incubated for 30 min with $5 \mathrm{e} \mathrm{mAb}(25 \mu \mathrm{g}$ 
of $\mathrm{IgG} / \mathrm{ml}$ ), which specifically recognizes chicken N-CAM, thus leaving the rat nerve substrata unstained. Mouse sensory neurons and their neurites were stained with the anti-N-cadherin antibody, which stained minimally the rat substrata. After two washes in PBS, cultures were incubated in biotinylated goat anti-mouse IgG (Amersham, Arlington Heights, IL) used at 1:50 dilution, and after they were rinsed, with alkaline phosphatase-conjugated streptavidin (Amersham) used at 1:300 dilution. Phosphatase activity was revealed using a nitro blue tetrazolium-bromochloroindolyl phosphate solution (Sigma). The reaction was stopped by adding EDTA to a final concentration of $20 \mu \mathrm{M}$. Slides were finally mounted with Moewiol. For confocal analysis of tissue section cultures, preparations were fixed, rinsed, and preincubated in milk/PBS solution as above. They were then sequentially incubated for $30 \mathrm{~min}$ with $5 \mathrm{e} \mathrm{mAb}(25 \mu \mathrm{g} \mathrm{IgG} / \mathrm{ml})$, biotinylated-goat anti-mouse $\mathrm{IgG}$ (Amersham) used at 1:50 dilution, and FITC-conjugated streptavidin (Amersham). Laminin immunoreactivity was then detected by a $30 \mathrm{~min}$ incubation with a rabbit anti-laminin antibody used at 1:500 dilution revealed, after washing, with TRITC-conjugated goat anti-rabbit IgG (Nordic Immunology).

\section{Confocal microscopy}

Stained cultures were mounted with Moewiol and examined on a Zeiss LSM410 laser scanning confocal microscope, using argon and heliumneon laser beams and appropriate filter combinations. The relationships of neurite trajectories with respect to their ECM environment were analyzed using simultaneous detection of FITC (axons) and TRITC (ECM molecules in the substrate). In most instances, separate $x-y$ scans were recorded at various depths. In some cases, however, extended depth of focus was used to compile successive scans along the entire depth of the preparation and thus reconstruct a general view of neuritic arborizations. Finally, $z$ scans, oriented perpendicular to the long axis of axon units in the tissue substratum, were obtained at various intervals to gain insight into the thickness of the preparation. In some experiments, myelin was visualized using the polarized $488 \mathrm{~nm}$ argon laser beam. Bright-field images of neurons labeled with the anti-NCAM antibody revealed with alkaline phosphatase were inverted, color-coded in green, and superimposed on the red-colored myelin images.

\section{RESULTS}

\section{Pattern of neurite outgrowth on sciatic nerve sections}

At first sight, no obvious differences were noted between normal and denervated nerve substrata in the way they influenced the patterning of neurite outgrowth of DRG neurons (Fig. 1), as already reported for younger embryonic chick neurons (Carbonetto et al., 1987). Neurons emitted profuse neuritic networks on both substrata, and in both cases neurites were mostly oriented along the long axis of the underlying, longitudinally cut nerve sections (Fig. 1), clearly indicating the prominent role of tissue structures in guiding nerve fibers. Preparations vitally stained with calcein-AM showed minimal contamination by nonneuronal cells, and neurites in their vicinity were not seen to grow preferentially over them.

In a first attempt to understand the reasons leading to such an oriented pattern of growth, the position of neurites was compared with that of myelin in the underlying substrata. Images of growing neurons stained with anti-N-CAM antibodies revealed with alkaline-phosphatase were acquired under transmitted light (Fig. $2 A$ ), inverted, and color-coded in green. Myelin in the same field was then imaged under polarized light (Fig. $2 B$ ) and color-coded in red. Superimposition of both images revealed that neurites showed a marked preference for substrate areas devoid of myelin. This was particularly clear on denervated nerve substrata, on which neurites were seen to extend outside the remaining patches of myelin debris (Fig. 2C).

To determine whether the compact nature of myelin sheaths could simply represent a physical barrier, impeding growth cones to invade the internal structures of axon units, neurons were grown on transverse sections of intact nerve. In this orientation,

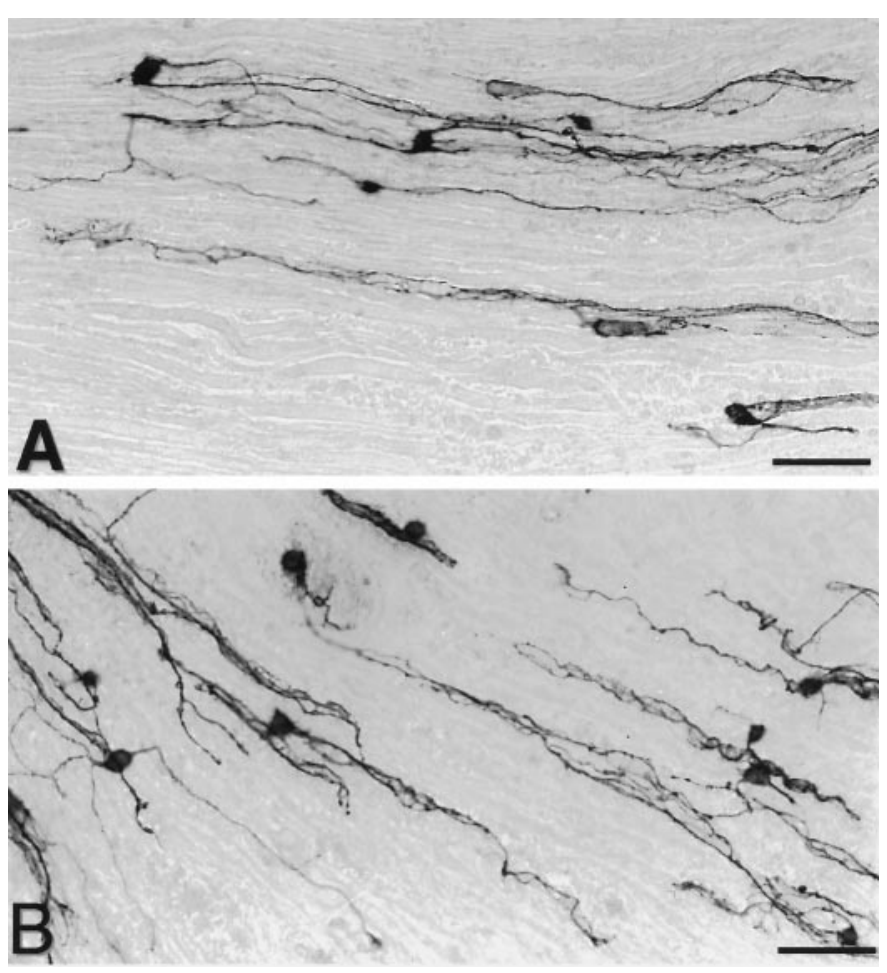

Figure 1. Characterization of neurite outgrowth of E13 chick sensory neurons grown for $48 \mathrm{hr}$ under control conditions on longitudinal sections obtained from normal rat nerves $(A)$ or from the distal portions of nerves transected 2 weeks before $(B)$. Neurons were stained with anti-chicken $\mathrm{N}-\mathrm{CAM}$ antibody (5e). On both types of substrata, neurons extend long processes oriented longitudinally. Scale bar, $100 \mu \mathrm{m}$.

the internal structure of most axon units is exposed at the surface of the tissue section and is directly accessible to nerve growth cones. Under these conditions, the pattern of neurite extension was strikingly different from that reported above: neurites did not form straight extensions but grew in successive loops and circles (Fig. 2D). Double immunofluorescence and confocal microscopy were then used to analyze the position of neurites with respect to other structures in tissular substrata. Neurons were stained with the anti-N-CAM antibody, and endoneurial basal laminae within the tissue sections were decorated with the anti-laminin-1/2 antiserum, which recognizes laminin-2 (merosin) in endoneurial basal laminae. It was striking to observe that most neurites grew in association with basal laminae. They were not found to extend across myelin sheaths enclosed within endoneurial tubes (Fig. $2 E, F)$. This was true even for the initial portions of primary neurites on their exit from the cell body (Fig. $2 E$ ). Interestingly, the same pattern was found several micrometers deeper, inside the tissue sections (Fig. $2 F$ ), indicating that growth was not confined to the surface of the substratum and that neurites were able to insinuate along basal lamina tubes.

\section{Relationships between growing neurites and basal laminae within tissue substrata}

The position of neurites with respect to that of endoneurial basal laminae was then compared between intact and denervated nerve substrata. Sensory neurons were grown on longitudinal nerve sections and the preparations were stained after $48 \mathrm{hr}$ using the same double immunofluorescence protocol as above. Observations under a conventional fluorescence microscope revealed that neurite extension was extensive along the laminin-2- 

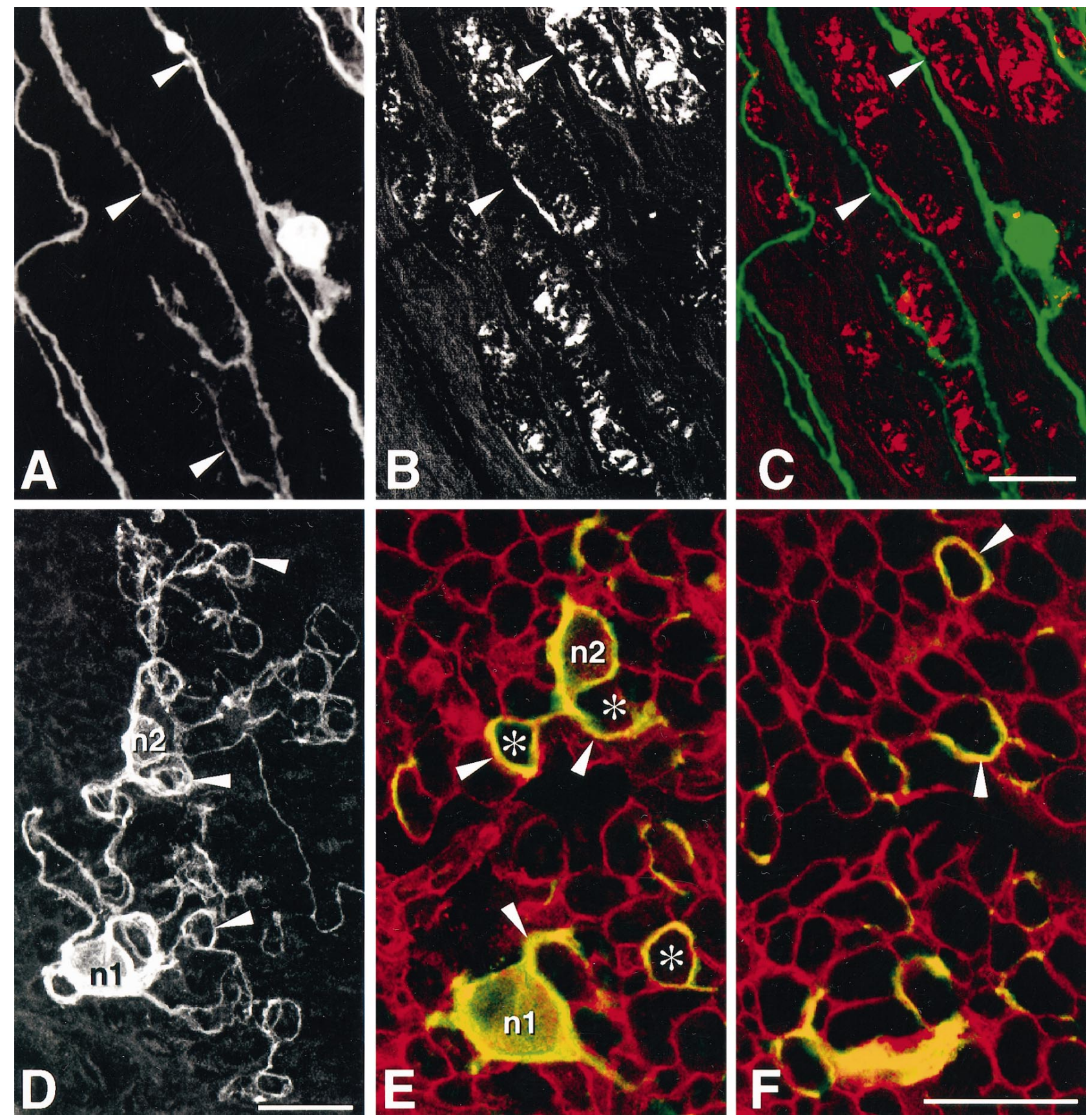

Figure 2. Growth of E13 chick sensory neurons on longitudinal sections of denervated sciatic nerve $(A-C)$ and on transverse sections of intact nerve $(D-F) . A-C$, Comparison of the pattern of neurite outgrowth with respect to the localization of myelin-rich areas in the underlying substratum. $A$, Neurons and their neurites (arrowheads) were stained with anti-N-CAM antibodies and alkaline phosphate conjugate, observed under transmitted light, as in Figure 1, and their image was inverted. B. Myelin in the same field was observed under polarized light. $C$, Superimposition of both images, after color coding neurons in green and myelin in red, reveals that in most instances neurites extend in areas devoid of myelin (arrowheads). $D-F$, Pattern of growth of two neurons ( $n 1$ and $n 2$ ) cultivated on transverse nerve sections and stained with anti-N-CAM antibodies. $D$, Total neuritic arborization. Neurites extend neurites that do not grow straight on the substratum but form loops (arrowheads). E, F, Confocal imaging of the same neurons. Neurons and their neurites stained with anti-N-CAM antibodies are displayed in green, whereas basal laminae stained with anti-laminin-1/2 antibodies are displayed in red. E. Horizontal optical section acquired at the surface of the substratum showing the base of the neuronal cell bodies $n 1$ and $n 2$ and the proximal part of their neurites (arrowheads). Note that neurites do not extend across the surface of the underlying axon units containing myelin (asterisks) but circle around, in association with laminin-stained endoneurial basal laminae. $F$, Horizontal optical section acquired $3 \mu \mathrm{m}$ deeper in the preparation. Neurites (arrowheads) extend deep inside the substratum but still do not cross myelin-containing axon units. Scale bars, $25 \mu \mathrm{m}$.

immunoreactive profiles of basal laminae, and was rarely found within extracellular spaces separating axon units. In some instances, neurites of a given neuron were entirely confined to a single axon unit of the substrate. Laminin-2 immunoreactivity was not clearly different between normal and denervated nerve substrata, confirming earlier observations (Sanes et al., 1990). To analyze in more detail the relationships between growing neurites and basal laminae, horizontal and transverse vertical optical sections of the double-stained preparations were acquired under a confocal microscope. This led to the following new observations. 
Figure 3. Confocal analysis of neurite outgrowth of embryonic chicken neurons cultivated on rat sciatic nerve sections. Cultures were fixed after $48 \mathrm{hr}$ and stained using an $\mathrm{mAb}$ directed against chicken N-CAM, revealed with FITC. Laminin-2 (merosin) in the substratum was decorated with an antiserum revealed with TRITC. $A-D$ and $1-4$, Culture on normal nerve section. $A$, Complete reconstruction, by extended depth of focus, of a growing neuron and underlying substratum, obtained by superimposition of consecutive images in the horizontal plane. The neuritic arborization (green) is confined to two adjacent Schwann cell tubes, defined by laminin-2 immunoreactive basal lamina scaffolds. $B-D$, Consecutive horizontal optical sections of the same neuron, obtained at $5 \mu \mathrm{m}$ intervals. The plane of image $C$ lies at midlevel of the Schwann cell tube. On normal nerve substratum, neurites extend in contact with laminin-immunoreactive basal laminae (arrows). Note in $C$ that they do not grow inside Schwann cell tubes. Insets 1-4, Successive vertical optical sections performed perpendicular to the long axis of Schwann cell tubes, along the lines 1-4 shown in $A$. Such optical sections confirm that neurites grow in contact with basal laminae (arrowheads) but do not extend inside Schwann cell tubes, despite the fact that some neurites are found deep inside the tissue section. $E-F$ and $1^{\prime}-4^{\prime}$, Culture on degenerated nerve section. $E$, Complete reconstruction as in $A$ of a growing neuron and underlying substratum. The neuritic arborization of the neuron seen on the right is confined to a single Schwann cell tube. Neurites of another neuron (cell body not visible in the micrograph) extend along a second basal lamina scaffold, on the left of the previous neuron. $F-H$, Consecutive horizontal optical sections of the same field, obtained at $5 \mu \mathrm{m}$ intervals. The plane of image $G$ lies at midlevel of the Schwann cell tube. On denervated substrata, neurites also extend in contact with laminin-immunoreactive basal laminae (arrows). However, note in $G$ that they grow profusely inside Schwann cell tubes. Insets 1'-4', Successive vertical optical sections performed perpendicular to the long axis of Schwann cell tubes, along the lines $1^{\prime}-4^{\prime}$ shown in $E$. Such optical sections confirm that on denervated nerve sections neurites grow not only in contact with basal laminae (arrowheads) but also extend inside Schwann cell tubes (arrows). Scale bars: $A-D, E-H, 25 \mu \mathrm{m} ; 1-4$ and $1^{\prime}-4^{\prime}, 10 \mu \mathrm{m}$.
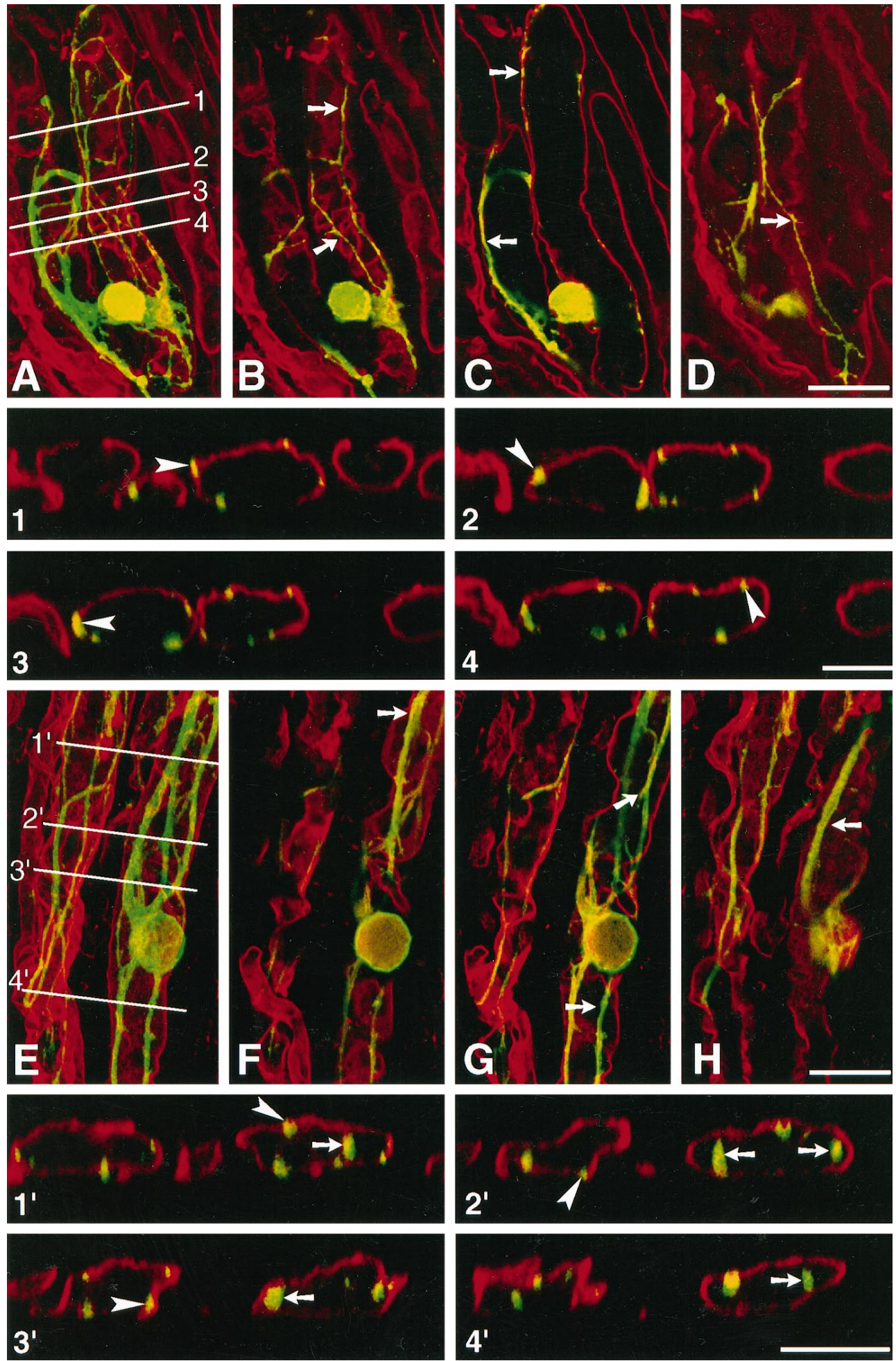

First, it confirmed that nerve fibers were not confined to the surface of the tissue sections but were able to grow within the tissue sections. In fact, neurites were observed extending in all horizontal planes, down to the deepest part of the cryosections (Fig. 3). Moreover, confocal microscopy revealed that in fact the localization of growing fibers was not identical between intact and denervated substrata. On normal nerve sections, as seen above for neurons growing on transverse nerve sections, neurites were associated with endoneurial basement membrane (Fig. 3B-D).
Few neurites were found outside of the endoneurial ECM scaffold, and none were ever observed deep inside basal lamina tubes (Fig. $3 C$ ). Vertical optical sections, performed perpendicular to the long axis of basal lamina tubes, confirmed these observations: most neurites were seen in direct association with the lamininimmunoreactive basal laminae (Fig. 3, insets 1-4). In marked contrast, on denervated nerve sections, neurites were found to extend not only along basal laminae (Fig. $3 F-H$ ) but also deep inside the axon units of the substratum (Fig. 3G). Transverse 


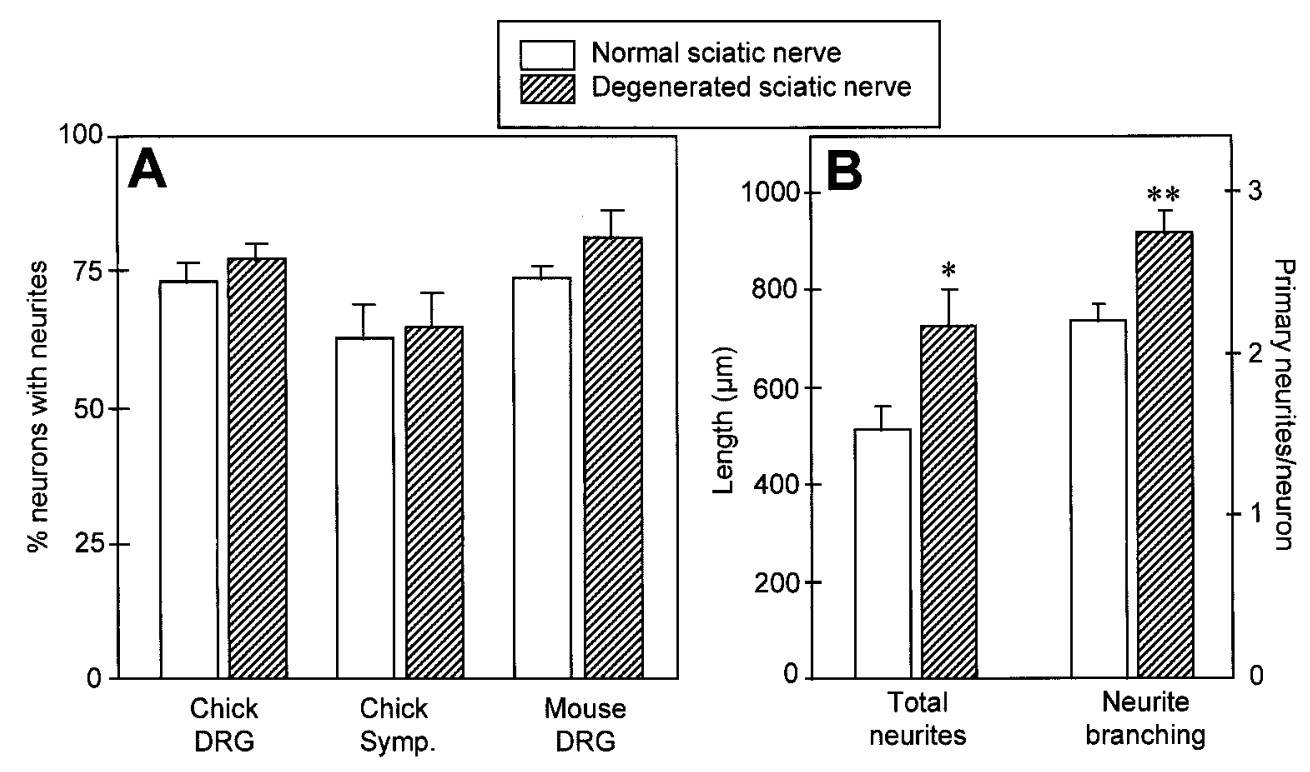

Figure 4. Comparison of neurite outgrowth on normal and degenerated sciatic nerve sections. $A$, Quantification of the number of growing E13 chick sensory neurons (Chick DRG), E13 chick sympathetic neurons (Chick Symp.), and newborn mouse sensory neurons (Mouse DRG), cultivated for 48 hr under control conditions on normal or degenerated sciatic nerve substrata. Values are the mean and SEM of the percentage of growing neurons, from at least three independent experiments. B, Quantification of total neuritic length and neurite branching of E13 chick sensory neurons grown on normal and degenerated sciatic nerve sections. Left $y$-axis: mean and SEM of total neuritic length elaborated per neuron (Total neurites); right $y$-axis: mean and SEM of the number of primary neurites elaborated per neuron (Neurite branching). Data were calculated from at least 120 neurons. Significance compared with normal sciatic nerve: ${ }^{*} p<0.05 ; * p<0.01$. Significance was analyzed using the Student's $t$ test.

optical sections helped to clarify these observations: whereas some fibers were seen, as above, in contact with basement membranes, others were found deep inside the oval-shaped profiles of endoneurial basal lamina scaffolds (Fig. 3, insets $1^{\prime}-4^{\prime}$ ). These data suggest that neurites are allowed to access the inner structures of endoneurial tubes after Wallerian degeneration.

\section{Quantification of neurite outgrowth on intact and denervated nerve substrata}

The above observations prompted us to reinvestigate, from a quantitative point of view, possible differences between normal and denervated environments in their ability to promote neurite outgrowth. Initial counts of chick DRG neurons showed that the percentage of neurons extending neurites was not significantly different on either degenerated or normal nerve substrates (Fig. $4 A$ ). To investigate whether this was a peculiarity of immature chick sensory neurons, the same experiment was repeated using E13 chick sympathetic neurons and newborn mouse DRG neurons. Again, for both neuronal types, the percentage of growing neurons was similar on normal or degenerated substrata (Fig. $4 A$ ). However, further analysis of neuronal growth taking into account the length of nerve fibers indicated that neurite outgrowth was significantly enhanced on lesioned nerve substrata compared with intact nerve substrata. For chick sensory neurons, for example (Fig. 4B), the average length of total neurites on denervated nerve substratum was $725 \mu \mathrm{m}$, a $42 \%$ increase compared with intact substratum $(511 \mu \mathrm{m})$. Similar scores were obtained for the other neuronal types (not shown). In addition, the number of primary neurites was also significantly enhanced, by $\sim 25 \%$, on denervated substrates compared with normal substrates, indicating a stimulation of neurite branching (Fig. 4B). Therefore, in our system, Wallerian degeneration not only allows neurites to access the internal structures of endoneurial tubes, as seen above, but it also stimulates the extent of neurite elongation and branching.

\section{Role of the $\beta 1$-integrin subunit}

The fact that practically all growing fibers were found in direct contact or in close proximity with the ECM of the basal lamina tubes, regardless of the intact or denervated status of the nerve substrata, prompted us to study the role of neuronal integrins in our system, and especially those containing the $\beta 1$ subunit, because they seem essential in mediating neurite elongation on various ECM molecules. For this we used function-blocking mAbs, JG22 and V2E9, which both recognize the chick $\beta 1$ integrin (Greve and Gottlieb, 1982; Tomaselli et al., 1986; Hayashi et al., 1990), and tested their effect on the growth of peripheral neurons cultivated on intact or lesioned sciatic nerve sections. In all of the following experiments, control cultures were performed by growing neurons from the same neuronal preparation that was used on tissue sections on laminin-1 or laminin-2 (merosin) substrata, with or without antibodies. Chick neurons grew equally well on laminin-1 purified from the mouse EHS tumor and human laminin-2 (Table 1), giving percentages of growth comparable to those observed on sciatic nerve substrata ( $\sim 70 \%$ of growing neurons), confirming that chick neuronal receptors recognize heterospecific ECM molecules. In these control cultures, JG22 and V2E9 antibodies at a concentration of 25 $\mu \mathrm{g} \mathrm{Ig} / \mathrm{ml}$ reduced drastically the number of sensory neurons growing on laminin-1. In addition, JG22 antibody also caused an important growth inhibition on laminin-2.

On sciatic nerve sections, both JG22 and V2E9 antibodies significantly reduced the number of neurons with neurites (Fig. $5 A$ ); inhibition by JG22 antibody was $45 \%$ on normal and $33 \%$ on degenerated substrata, whereas inhibition by V2E9 antibody was $40 \%$ on normal and $39 \%$ on degenerated substrata. This substantial reduction of neurite outgrowth was not restricted to sensory neurons, because JG22 antibody also diminished the percentage of growing sympathetic neurons by $36 \%(n=3)$ on normal sciatic nerve substratum and by $27 \%(n=2)$ on degenerated sciatic 
Table 1. Effect of anti- $\beta 1$-integrin antibodies on neurite outgrowth of sensory neurons grown for $48 \mathrm{hr}$ in Terasaki dishes on laminin substrata

\begin{tabular}{|c|c|c|c|c|c|}
\hline \multirow[b]{3}{*}{$\begin{array}{l}\text { Substrate } \\
\text { molecule }\end{array}$} & \multirow{3}{*}{$\begin{array}{l}\text { Control } \\
\text { Growing } \\
\text { neurons }^{a}\end{array}$} & \multicolumn{4}{|l|}{ Antibody } \\
\hline & & \multicolumn{2}{|l|}{ JG22 } & \multicolumn{2}{|l|}{ V2E9 } \\
\hline & & $\begin{array}{l}\text { Growing } \\
\text { neurons }{ }^{a}\end{array}$ & $\begin{array}{l}\text { Percentage of } \\
\text { inhibition }^{b}\end{array}$ & $\begin{array}{l}\text { Growing } \\
\text { neurons }{ }^{a}\end{array}$ & $\begin{array}{l}\text { Percentage of } \\
\text { inhibition }^{b}\end{array}$ \\
\hline Laminin-1 & $69.9 \pm 4.9$ & $8.4 \pm 3$ & $88^{c}$ & $30.1 \pm 4$ & $57^{d}$ \\
\hline Laminin-2 & $65.6 \pm 14$ & $27.6 \pm 11$ & $58^{e}$ & ND & ND \\
\hline
\end{tabular}

\footnotetext{
ND, Not determined.

${ }^{a}$ Mean \pm SEM of the percentage of neurons with neurites, determined from at least three independent experiments.

${ }^{b}$ Percentage of inhibition compared with the corresponding control.

${ }^{c-e}$ Significance compared with the corresponding control. ${ }^{c} p \leq 0.001 ;{ }^{d} p \leq 0.005 ;{ }^{e} p \leq 0.05$.
}

nerve substratum (not shown). A control mAb A2B5, directed against a common neuronal membrane epitope not involved in neurite outgrowth and expressed by chick DRG neurons, was without effect, indicating that the observed results were not attributable to steric hindrance or another nonspecific role of the antibodies.

To document further this blocking effect, neurite length was measured for neurons growing in the presence of JG22 (Fig. 5B). The anti- $\beta 1$-integrin antibody caused a $42 \%$ decrease in total neurite length on normal sciatic nerve substratum and a $44 \%$ decrease on degenerated sciatic nerve sections. Moreover, antibody treatment also significantly reduced on both substrata the number of primary neurites per neuron (see Table 3 ). These results strongly suggest that interactions involving integrins containing the $\beta 1$ subunit play an important role in mediating neurite regeneration in the PNS milieu. Accordingly, we sought to determine the respective roles of laminin-1, merosin, and fibronectin in this process, matrix molecules that are all recognized by integrins containing the $\beta 1$ subunit and are active promoters of neurite outgrowth in vitro.

\section{Role of fibronectin and laminins}

To analyze the role of fibronectin, we have used a purified antiserum directed against rat plasma fibronectin, which efficiently reduces neurite outgrowth from chick sensory neurons grown on control rat fibronectin substratum (Table 2). On normal sciatic nerve, this antibody had no effect on neurite outgrowth (Fig. 6). On degenerated sciatic nerve sections, it affected neither the number of growing neurons (Fig. 6A) nor neurite length (Fig. $6 B$ ), but it significantly reduced by $25 \%$ the number of primary neurites emitted per neuron (Table 3 ).

To test the role of laminin-2/merosin, we used an antiserum originally directed against laminin-1 (Carbonetto et al., 1987), which also strongly cross-reacts with laminin-2, as shown by its ability to stain intensely endoneurial basal laminae (Fig. 3). We also used an mAb directed against the $\alpha 2$ chain of human merosin, from commercial source, which on Western blots crossreacts with rat laminin-2 (not shown). Both reagents were first tested for their ability to block laminin-induced neurite outgrowth (Table 2). The anti-laminin-1/2 antiserum readily blocked neurite outgrowth of DRG neurons grown on laminin-1 substratum by $>60 \%$ and caused a lower inhibition $(\sim 40 \%)$ on laminin$2 /$ merosin substratum. The anti-laminin- 2 antibody reduced by the same level the percentage of neurons growing on laminin-2 and was without effect on laminin-1 (Table 2).

On normal sciatic nerve substrata, none of these antibodies significantly changed the growth of peripheral neurons: they did not diminish the percentage of growing neurons (Fig. 6A) and did not affect neurite length (Fig. 6B) or the number of primary neurites per neurons (Table 3). Surprisingly, however, both antibodies perturbed neurite outgrowth on denervated nerve sections. First, although the anti-laminin-1/2 did not affect the percentage of growing neurons, the anti-laminin- 2 antibody caused a $40 \%$ reduction in this number (Fig. 6A). The reason for this discrepancy between the two antibodies is unclear, given their equal effect on laminin substrata (Table 2). However, both antibodies diminished almost by half the length of neurites on lesioned sciatic nerve (Fig. 6B) and reduced significantly the number of primary neurites per neuron (Table 3 ). Similar results were obtained with both antibodies using chick sympathetic neurons (not shown). These experiments demonstrate that two different anti-laminin-2 antibodies can greatly reduce the growth of regenerating nerve fibers confronted with a lesioned nerve environment, but they are totally inefficient to perturb growth elicited by an intact peripheral nerve substratum.

\section{DISCUSSION}

Cultures of embryonic or adult neurons on histological sections of peripheral nerves have been used previously to study mechanisms responsible for neurite extension in this particular environment (Carbonetto et al., 1987; Bedi et al., 1992; Shewan et al., 1993; Anton et al., 1994; Tuttle and Matthew, 1995). Our observations confirm these studies and indicate that sciatic nerve sections are able to stimulate nerve fiber elongation to a level comparable to that observed with laminin substrata. In addition, nerve fiber growth was clearly directed by the tissular organization of the substrata, suggesting that as in vivo, spatially restricted cues within the tissue environment play a major role in controlling growth patterns.

In most of the present experiments, E13 chick DRG neurons were used. At this stage, the development of the chick nervous system is comparable to that of a newborn rodent (Agius et al., 1996), and similar scores of growth were obtained for E13 chick and newborn mouse neurons. This result is in agreement with previous analyses that also used heterospecific combinations of growing neurons and tissue substrata (Savio and Schwab, 1989; Bastmeyer et al., 1991; Sagot et al., 1991; Tuttle and Matthew, 1995). More generally, cryoculture studies using various interspecific combinations have not revealed significant differences with monospecific neuron-substratum associations (for references, see Crutcher, 1993), and a number of examples show that substrate preferences are not species dependent (Godement and Bonhoeffer, 1989; Bastmeyer et al., 1991). This further strengthens the 

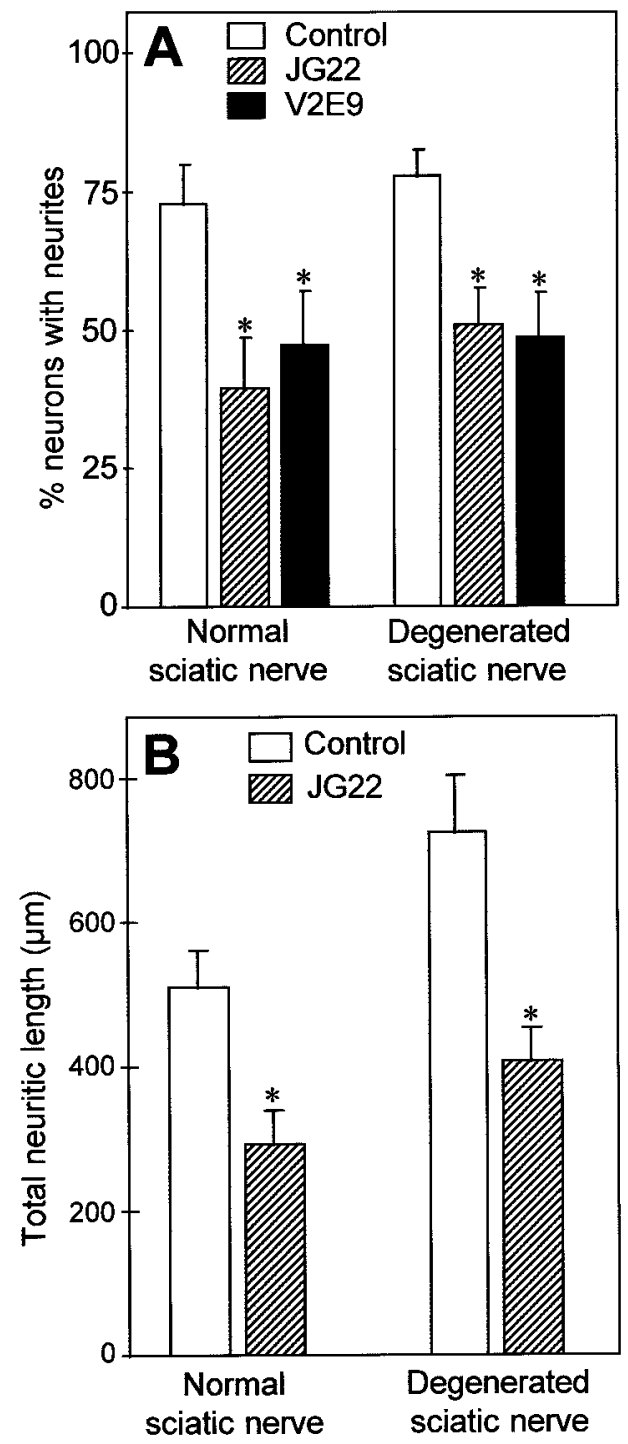

Figure 5. Inhibition of neurite outgrowth of E13 chick sensory neurons by two different antibodies, JG22 and V2E9, directed against chick $\beta 1$ integrin subunit, on each type of nerve substratum. The concentrations used were $25 \mu \mathrm{g} \mathrm{Ig} / \mathrm{ml}$ for both antibodies. The blocking ability of each antibody was controlled with the same neuronal preparations grown on laminin- 1 or laminin-2, and the corresponding results are shown in Table 1. A, Quantification of the number of neurons extending neurites after $2 \mathrm{~d}$ of culture. Values represent mean and SEM of the percentage of growing neurons for five different experiments. $B$, Quantification of neurite length Values represent the mean and SEM of total neuritic length elaborated per neuron, measured for at least 120 neurons. ${ }^{*} p<0.05$. Significance was analyzed using the Student's $t$ test.

notion that the recognition of growth-promoting and -inhibiting molecules is highly conserved among vertebrates.

Our first objective was to compare the ability of intact and denervated nerve substrata to promote fiber growth. Our results clearly demonstrate quantitative and qualitative differences between the two substrata. First, compared with normal nerve, denervated nerve substrata enhanced, by $\sim 40 \%$, the length of nerve fibers. Second, our experiments using confocal microscopy showed that neurites extended and navigated deep inside axon units of the substratum on denervated nerve sections but were never able to do so on intact nerve sections. It should be pointed out, however, that the resolution of the confocal microscope did not permit determination of whether on normal nerve sections neurites extended on the inside or outside walls of the basal lamina tubes. Nevertheless, the increased neurite growth measured on denervated nerve sections is directly correlated with the ability of nerve fibers to extend deep inside Schwann cell tubes.

What could prevent neurites from entering Schwann cell tubes in sections of intact nerve? In our assay, most neurites were unable to grow in myelin-rich areas in tissue substrata, raising the possibility that myelin could negatively control neurite extension. It seems unlikely that this could be attributable to the compact nature of myelin sheaths, as suggested by the pattern of growth observed on transverse sections of intact nerve. Myelin-associated glycoprotein (MAG), a component of peripheral nerve myelin, has been shown to present growth inhibitory properties (Mac Kerracher et al., 1994; Mukhopadhyay et al., 1994). However, in those experiments, MAG inhibited only the growth of adult sensory neurons but promoted that of newborn neurons (Mukhopadhyay et al., 1994). Therefore, if myelin plays any role in controlling neurite outgrowth in our system, which remains to be established, factors others than MAG should be implicated.

Regardless of the mechanism involved, it seems clear, as stated above, that the denervated status of the nerve substratum allows penetration of neurites deep inside endoneurial Schwann cell tubes, a situation also routinely observed during axonal regeneration in vivo (Ide et al., 1983). This further strengthens the idea that the cryoculture paradigm is well fitted to study mechanisms of nerve regeneration. In addition, this demonstrates that neurites exposed to a denervated substratum have access to a different environment than that in intact nerve sections. Such an access to growth-promoting factors possibly present or accumulated inside endoneurial Schwann cell tubes, together with the disappearance of myelin, may well be two essential reasons responsible for the stimulation of growth observed over denervated nerve substrates.

In this context, the results of perturbation experiments with anti-laminin antibodies seem particularly significant. Members of the laminin family, and in particular laminin-1 and its laminin-2/ merosin isoform, are believed to play an important role in neuritogenesis (for review, see Venstrom and Reichardt, 1993; Luckenbill-Edds, 1997). Laminin-2, constituted by the association of its specific $\alpha 2$ chain with the $\beta 1$ and $\gamma 1$ chains also found in laminin-1, is expressed by Schwann cells (Leivo and Engvall, 1988; LeBeau et al., 1994) and represents the predominant form of laminin in peripheral nerves (Sanes et al., 1990). Antibodies directed against the ARM-1 antigen, believed to be laminin-2, have already been shown by a similar cryoculture approach to block a large fraction of neurite outgrowth induced by denervated nerve substrata (Anton et al., 1994). Our own experiments confirm and extend these data, because reduction in neurite outgrowth was observed only for denervated nerve substrates. The lack of inhibition on normal nerve substrates could result from a difference in the level of laminin in endoneurial basal laminae between the two types of substrata. This is unlikely, however, because denervation had no effect on the distribution or level of laminin immunoreactivity in endoneurial basal laminae, a finding in agreement with previous results (Sanes et al., 1990). Our data rather suggest that the important inhibition noted on denervated nerve sections is related to the ability of nerve fibers to enter endoneurial basal lamina tubes. In this respect, it is interesting to mention results strongly suggesting that laminin is mostly localized at the internal surface of endoneurial basal lamina tubes (Ide et al., 1983; Tohyama and Ide, 1984). Accordingly, an important fraction of the additional growth induced by denervated nerve 
Table 2. Test of anti-ECM molecule antibodies on neurite outgrowth of sensory neurons grown for 48 hr in Terasaki dishes on the corresponding ECM substrata

\begin{tabular}{|c|c|c|c|c|c|c|c|}
\hline \multirow[b]{2}{*}{$\begin{array}{l}\text { Substrate } \\
\text { molecule }\end{array}$} & \multirow[b]{2}{*}{$\begin{array}{l}\text { Control growth } \\
\text { (no antibody) }\end{array}$} & \multicolumn{2}{|c|}{ Anti-fibronectin } & \multicolumn{2}{|c|}{ Anti-laminin-1 } & \multicolumn{2}{|c|}{ Anti-laminin-2 } \\
\hline & & $\begin{array}{l}\text { Growing } \\
\text { neurons }^{a}\end{array}$ & $\begin{array}{l}\text { Percentage of } \\
\text { inhibition }^{b}\end{array}$ & $\begin{array}{l}\text { Growing } \\
\text { neurons }^{a}\end{array}$ & $\begin{array}{l}\text { Percentage of } \\
\text { inhibition }^{b}\end{array}$ & $\begin{array}{l}\text { Growing } \\
\text { neurons }^{a}\end{array}$ & $\begin{array}{l}\text { Percentage of } \\
\text { inhibition }^{b}\end{array}$ \\
\hline Fibronectin & $45.7 \pm 7.4$ & $27 \pm 5$ & $40.9^{c}$ & & & & \\
\hline Laminin-1 & $82.5 \pm 3.6$ & & & $31.6 \pm 4.6$ & $61.7^{d}$ & $80.3 \pm 5.5$ & 2.7 \\
\hline Laminin-2 & $68.1 \pm 12.4$ & & & $41.3 \pm 12$ & $39.3^{e}$ & $42.7 \pm 11.1$ & $37.3^{e}$ \\
\hline
\end{tabular}

${ }^{a}$ Mean \pm SEM of the percentage of neurons with neurites, determined from at least three independent experiments.

${ }^{b}$ Percentage of inhibition compared with the corresponding control.

${ }^{c-e}$ Significance corresponding to the corresponding control. ${ }^{c} p \leq 0.005 ;{ }^{d} p \leq 0.001 ;{ }^{e} p \leq 0.05$.

substrata could be attributable to increased accessibility of laminin for growth cones.

What could be the factors responsible for the growth of embryonic neurons on intact nerve substrata? Perturbation experiments using antibodies directed against $\beta 1$-integrins, ubiquitous receptors for numerous matrix molecules, indicate that such molecules are involved. In vivo experiments using anti-integrin antibodies suggested that integrins of the $\beta 1$ class are involved in controlling axonal regeneration in peripheral nerves (Toyota et al., 1990). However, it was difficult in such experiments to know whether the antibodies directly blocked growth cone progression or indirectly perturbed important cellular events that occur during Wallerian degeneration, such as Schwann cell locomotion or macrophage invasion. Our results, obtained on a "passive" environment, demonstrate that neuronal $\beta 1$-integrins play an important part in controlling nerve fiber regeneration in the PNS environment.

In addition to laminins, neuronal $\beta 1$-integrins regulate fiber growth over fibronectin (for review, see Diamond and Springer, 1994), which is prominently expressed in the endoneurial ECM (Lefcort et al., 1992). Fibronectin accumulates outside the basal laminae surrounding axon units (Wang et al., 1992) and is overexpressed after lesion (Lefcort et al., 1992). However, we did not observe significant effects with function-blocking antibodies directed against fibronectin, neither on the number of neurons with neurites nor on neurite length. Nevertheless, it is interesting to note that these antibodies reduced the number of primary neurites per neuron, but only on denervated nerve substrata. In our culture conditions, therefore, fibronectin does not appear to play an essential role in promoting neurite outgrowth on sciatic nerve sections. Our observations suggest a more subtle role, perhaps restricted to early steps in the process of neurite formation.

Other ECM molecules that bind to $\beta 1$-integrins could be considered potential candidates for mediating this $\beta 1$-integrinmediated growth, including tenascin and thrombospondin (Neugebauer et al., 1991; Faissner et al., 1994; Varnum-Finney et al., 1995). Specific tenascin isoforms, which promote neurite outgrowth in vitro (Wehrle and Chiquet, 1990) are present in adult nerves, especially at the level of the nodes of Ranvier (Rieger et al., 1986; Martini et al., 1990). In addition, specific isoforms are overexpressed after lesion and accumulate in the distal nerve stump, suggesting that tenascin might play a role during nerve repair (Daniloff et al., 1989; Martini et al., 1990; Zhang et al., 1995). However, after axotomy, the regeneration of the sciatic nerve is not altered in transgenic mice lacking tenascin-C (Forsberg et al., 1996), and regenerating peripheral axons are not always associated with tenascin in endoneurial tubes (Zhang et al., 1995; our unpublished data). Therefore the role of tenascin in

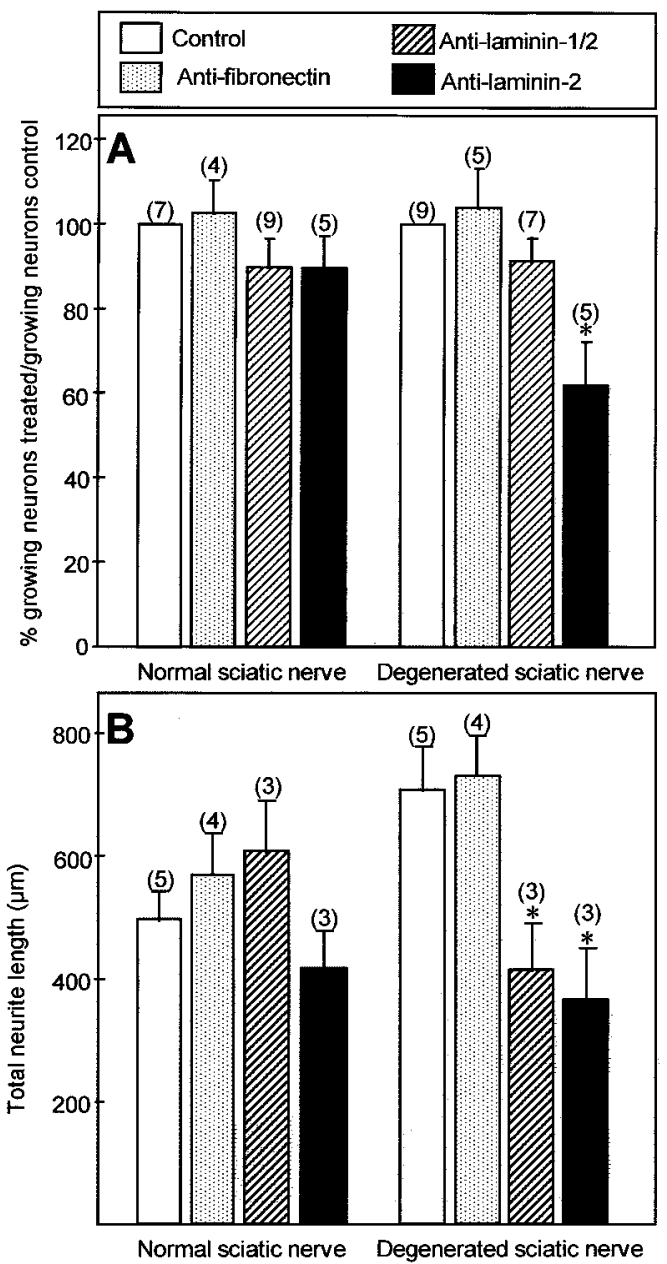

Figure 6. Effects of anti-fibronectin, anti-laminin-1/2, and anti-laminin-2 antibodies on neurite outgrowth of E13 chick sensory neurons grown for $48 \mathrm{hr}$ on normal and degenerated sciatic nerve substrata. For laminin-1/2 and fibronectin, at least two different antibodies were tested, with concentrations between 25 and $50 \mu \mathrm{g} \mathrm{Ig} / \mathrm{ml}$, yielding similar results. The blocking ability of each antibody was controlled with the same neuronal preparations grown on the corresponding ECM molecule, and the corresponding results are shown in Table 2. A, Quantification of the number of neurons extending neurites after $2 \mathrm{~d}$ of culture. Values represent mean and SEM of the percentage of growing neurons in treated conditions normalized to the number of growing neurons in control cultures $(100 \%)$ for the number of experiments indicated in parentheses. B, Quantification of neurite length. Values represent the mean and SEM of total neuritic length elaborated per neuron, measured for at least 100 neurons. ${ }^{*} p<$ 0.05 . Significance was analyzed using the Student's $t$ test. 
Table 3. Effects of anti- $\beta 1$-integrin antibodies (JG22) and of anti-ECM molecule antibodies on the number of primary neurites elaborated per sensory neuron, cultivated on sections of normal and degenerated sciatic nerve

\begin{tabular}{llllll} 
& \multicolumn{2}{l}{ Normal sciatic nerve } & & \multicolumn{2}{l}{ Degenerated sciatic nerve } \\
\cline { 2 - 3 } & $\begin{array}{l}\text { Primary neurites } \\
\text { per neuron }\end{array}$ & $\begin{array}{l}\text { Percentage } \\
\text { of inhibition }^{b}\end{array}$ & & $\begin{array}{l}\text { Primary neurites } \\
\text { per neuron }\end{array}$ & $\begin{array}{l}\text { Percentage } \\
\text { of inhibition }^{b}\end{array}$ \\
\hline Control $(n=5)^{c}$ & $2.21 \pm 0.1(127)$ & & $2.76 \pm 0.12(122)^{d}$ & \\
JG22 $(n=3)$ & $1.77 \pm 0.06(102)$ & $19.9^{e}$ & & $1.91 \pm 0.08(130)$ & $30.8^{e}$ \\
Anti-fibronectin $(n=4)$ & $1.96 \pm 0.08(124)$ & $\mathrm{ns}$ & & $2.06 \pm 0.09(128)$ & $25.4^{e}$ \\
Anti-laminin-1 $(n=3)$ & $2.09 \pm 0.09(101)$ & $\mathrm{ns}$ & & $2.14 \pm 0.11(114)$ & $22.5^{e}$ \\
Anti-laminin-2 $(n=3)$ & $2.23 \pm 0.11(92)$ & $\mathrm{ns}$ & & $2.14 \pm 0.1(88)$ & $22.5^{e}$ \\
\hline
\end{tabular}

ns, Not significant. Significance was analyzed using the Student's $t$ test.

${ }^{a}$ Mean \pm SEM of the number of primary neurites per neuron, measured for the number of neurons indicated in parentheses.

${ }^{b}$ Percentage of inhibition compared with the corresponding control, specified only in the case of significant differences.

${ }^{c}$ Number of different experiments from which the measured neurons were pooled.

${ }^{d}$ Significance compared with normal sciatic nerve control: $p \leq 0.01$.

${ }^{e}$ Significance compared with the corresponding control: $p \leq 0.01$.

this system remains to be explored further. Similarly, molecules of the thrombospondin family that interact with $\beta 1$-integrins (Neugebauer et al., 1991; DeFreitas et al., 1995) are also expressed in peripheral nerves (O'Shea and Dixit, 1988; Hoffman et al., 1994) and have been shown to support peripheral neurite outgrowth in vitro (Neugebauer et al., 1991; O'Shea et al., 1991; Osterhout et al., 1992; Arber and Caroni, 1995). Interestingly, a correlation in various species between the presence of thrombospondin and a potential for successful nerve regeneration has been reported (Hoffman et al., 1994). Therefore, further experiments are required to determine the role of these molecules in neurite regeneration in the PNS.

\section{REFERENCES}

Agius E, Sagot Y, Duprat AM, Cochard P (1996) Antibodies directed against the $\beta 1$-integrin subunit and peptides containing the IKVAV sequence of laminin perturb neurite outgrowth of peripheral neurons on immature spinal cord substrata. Neuroscience 71:773-786.

Anton ES, Sandrock AJ, Matthew WD (1994) Merosin promotes neurite growth and Schwann cell migration in vitro and nerve regeneration in vivo: evidence using an antibody to merosin, ARM-1. Dev Biol 164:133-146.

Arber S, Caroni P (1995) Thrombospondin-4, an extracellular matrix protein expressed in the developing and adult nervous system, promotes neurite outgrowth. J Cell Biol 131:1083-1094.

Bastmeyer M, Beckmann M, Schwab ME, Stuermer CAO (1991) Growth of regenerating goldfish axons is inhibited by rat oligodendrocytes and CNS myelin but not by goldfish optic nerve tract oligodendrocyte-like cells and fish myelin. J Neurosci 11:626-640.

Bedi KS, Winter J, Berry M, Cohen J (1992) Adult rat dorsal root ganglion neurons extend neurites on predegenerated but not normal peripheral nerves in vitro. Eur J Neurosci 4:193-200.

Carbonetto S, Evans D, Cochard P (1987) Nerve fiber growth in culture on tissue substrata from central and peripheral nervous system. J Neurosci 7:610-620.

Cornbrooks CJ, Carey DJ, McDonald JA, Timpl R, Bunge R (1983) In vivo and in vitro observation of laminin production by Schwann cells. Proc Natl Acad Sci USA 80:3850-3854.

Covault J, Cunningham JM, Sanes JR (1987) Neurite outgrowth on cryostat sections of innervated and denervated skeletal muscle. J Cell Biol 105:2479-2488.

Crutcher KA (1989) Tissue sections from the mature brain and spinal cord as substrates for neurite outgrowth in vitro: extensive growth on gray matter but little growth on white matter. Exp Neurol 104:39-54.

Crutcher KA (1993) Tissue sections as culture substrates: overview and critique. Hippocampus 3:157-164.

Daniloff JK, Crossin KL, Pincon RM, Murawsky M, Rieger F, Edelman GM (1989) Expression of cytotactin in the normal and regenerating neuromuscular system. J Cell Biol 108:625-635.
DeFreitas MF, Yoshida CK, Frazier WA, Mendrick DL, Kypta RM, Reichardt LF (1995) Identification of integrin $\alpha 3 \beta 1$ as a neuronal thrombospondin receptor mediating neurite outgrowth. Neuron 15:333-343.

Diamond MS, Springer TA (1994) The dynamic regulation of integrin adhesiveness. Curr Biol 4:506-517.

Faissner A, Scholze A, Götz B (1994) Tenascin glycoprotein in developing neural tissues: only decoration? Perspect Dev Neurobiol 2:53-56.

Fawcett JW, Keynes RJ (1990) Peripheral nerve regeneration. Annu Rev Neurosci 13:43-60.

Forsberg E, Hirsch E, Frohlich L, Meyer M, Ekblom P, Aszodi A, Werner S, Fassler R (1996) Skin wounds and severed nerves heal normally in mice lacking tenascin-C. Proc Natl Acad Sci USA 93:6594-6599.

Godement P, Bonhoeffer T (1989) Cross-species recognition of tectal cues by retinal fibers in vitro. Development 106:313-320.

Greve JM, Gottlieb DI (1982) Monoclonal antibodies which alter the morphology of chick myogenic cells. J Cell Biochem 18:221-229.

Haas TA, Plow EF (1994) Integrin-ligand interactions: a year in review. Curr Opin Cell Biol 6:656-662.

Hayashi Y, Haimovich B, Reszka A, Boettiger D, Horwitz A (1990) Expression and function of chicken integrin $\beta 1$ subunit and its cytoplasmic domain mutants in mouse NIH 3T3 cells. J Cell Biol 110:175-184.

Hoffman JR, Dixit VM, O'Shea KS (1994) Expression of thrombospondin in the adult nervous system. J Comp Neurol 340:126-139.

Ide C, Tohyama K, Nitatori T, Onodera S (1983) Schwann cell basal lamina and nerve regeneration. Brain Res 288:61-75.

Kauppila T, Jyväsjärvi E, Huopaniemi T, Hujanen E, Liesi P (1993) A laminin graft replaces neurorrhaphy in the restorative surgery of the rat sciatic nerve. Exp Neurol 123:181-191.

Langley JN, Anderson HK (1904) The union of different kinds of nerve fiber. J Physiol (Lond) 31:365-391.

LeBeau JM, Liuzzi FJ, Depto AS, Vinik AI (1994) Differential laminin gene expression in dorsal root ganglion neurons and nonneuronal cells. Exp Neurol 127:1-8.

Lefcort F, Venstrom K, McDonald JA, Reichardt LF (1992) Regulation of expression of fibronectin and its receptor $\alpha 5 \beta 1$, during development and regeneration of peripheral nerve. Development 116:767-782.

Leivo I, Engvall E (1988) Merosin, a protein specific for basement membranes of Schwann cells, striated muscle, and trophoblast, is expressed late in nerve and muscle development. Proc Natl Acad Sci USA 85:1544-1548.

Luckenbill-Edds L (1997) Laminin and the mechanism of neuronal outgrowth. Brain Res Rev 23:1-27.

Mac Kerracher L, David S, Jackson DL, Kottis V, Dunn RJ, Braun PE (1994) Identification of myelin-associated glycoprotein as a major myelin-derived inhibitor of neurite growth. Neuron 13:805-811.

Martini R, Schachner M, Faissner A (1990) Enhanced expression of the extracellular matrix molecule $\mathrm{J} 1 /$ tenascin in the regenerating adult mouse sciatic nerve. J Neurobiol 19:601-616.

Mukhopadhyay G, Doherty P, Walsh FS, Crocker PR, Filbin MT (1994) 
A novel role for myelin-associated glycoprotein as an inhibitor of axonal regeneration. Neuron 13:757-767.

Neugebauer KM, Emmett CJ, Venstrom KA, Reichardt LF (1991) Vitronectin and thrombospondin promote retinal neurite outgrowth: developmental regulation and role of integrins. Neuron 6:345-358.

O'Shea KS, Dixit VM (1988) Unique distribution of the extracellular matrix component thrombospondin in the developing mouse embryo. J Cell Biol 107:2737-2748.

O'Shea KS, Liu LHJ, Dixit VM (1991) Thrombospondin and a $140 \mathrm{kd}$ fragment promote adhesion and neurite outgrowth from embryonic central and peripheral neurons and from PC12 cells. Neuron 7:231-237.

Osterhout DJ, Frazier WA, Higgins D (1992) Thrombospondin promotes process outgrowth in neurons from the peripheral and central nervous system. Dev Biol 150:256-265.

Ramon y Cajal S (1928) Degeneration and regeneration of the nervous system (May RM, ed). Oxford: Oxford UP.

Rieger F, Daniloff JK, Pincon-Raymond M, Crossin KL, Grumet M, Edelman GM (1986) Neuronal cell adhesion molecules and cytotactin are colocalized at the node of Ranvier. J Cell Biol 1003:379-391.

Sagot Y, Swerts JP, Cochard P (1991) Changes in permissivity for neuronal attachment and neurite outgrowth of spinal cord grey and white matters during development: a study with the "cryoculture" bioassay. Brain Res 543:25-35.

Sandrock AW, Matthew WD (1987) Identification of a peripheral nerve neurite growth-promoting activity by development and use of an in vitro bioassay. Proc Natl Acad Sci USA 84:6934-6938.

Sanes JR, Engvall E, Butkowski R, Hunter DD (1990) Molecular heterogeneity of basal laminae: isoforms of laminin and collagen IV at the neuromuscular junction and elsewhere. J Cell Biol 111:1685-1699.

Savio T, Schwab ME (1989) Rat CNS white matter, but not gray matter, is nonpermissive for neural cell adhesion and fiber outgrowth. J Neurosci 9:1126-1133.
Shewan D, Berry M, Bedi KS, Cohen J (1993) Embryonic optic nerve tissue fails to support neurite outgrowth by central and peripheral neurons in vitro. Eur J Neurosci 5:809-817.

Tohyama K, Ide C (1984) The localization of laminin and fibronectin on the Schwann cell basal lamina. Arch Histol Jpn 47:519-532.

Tomaselli KJ, Reichardt LF, Bixby JL (1986) Distinct molecular interactions mediate neuronal process outgrowth on non-neuronal cell surfaces and extracellular matrices. J Cell Biol 103:2659-2672.

Toyota B, Carbonetto S, David S (1990) A dual laminin/collagen receptor acts in peripheral nerve regeneration. Proc Natl Acad Sci USA 87:1319-1322.

Tuttle R, Matthew WD (1995) Neurotrophins affect the pattern of DRG neurite outgrowth in a bioassay that presents a choice of CNS and PNS substrates. Development 121:1301-1309.

Varnum-Finney B, Venstrom K, Muller U, Kypta R, Backus C, Chiquet M, Reichardt LF (1995) The integrin receptor $\alpha 8 \beta 1$ mediates interactions on embryonic chick motor and sensory neurons with tenascin-C. Neuron 14:1213-1222.

Venstrom KA, Reichardt LF (1993) Extracellular matrix 2: role of extracellular matrix molecules and their receptors in the nervous system. FASEB J 7:996-1003.

Wang GY, Hirai K, Shimada H, Taji S, Zhong SZ (1992) Behavior of axons, Schwann cells and perineurial cells in nerve regeneration within transplanted nerve grafts: effects of anti-laminin and anti-fibronectin antisera. Brain Res 583:216-226.

Wehrle B, Chiquet M (1990) Tenascin is accumulated along developing peripheral nerves and allows neurite outgrowth in vitro. Development 110:401-415.

Zhang Y, Campbell G, Anderson PN, Martini R, Schachner M, Lieberman AR (1995) Molecular basis of interactions between regenerating adult rat thalamic axons and Schwann cells in peripheral nerve grafts. II. Tenascin-C. J Comp Neurol 361:210-224. 